\title{
Future Trend Toward the Ultimate Goal of Radwaste-Free Fusion: Feasibility of Recycling/Clearance, Avoiding Geological Disposal ${ }^{*}$
}

\author{
Laila A. EL-GUEBALY \\ University of Wisconsin-Madison, Madison, WI 53706, USA
}

(Received 19 June 2012 / Accepted 18 September 2012)

\begin{abstract}
Electricity generating plants powered by fusion have long been envisioned as possessing inherent advantages for enhanced safety and benign environmental impact over the presently used fuels. However, fusion power plant designs developed to date tend to generate a sizable amount of mildly radioactive materials, compared to fission reactors. Proper handling of the anticipated quantities of activated materials is important to the future of fusion energy. The problem of handling such materials has been overlooked in many past fusion studies and/or relegated to the back-end as only a disposal issue. In fact, the geological disposal is not an environmentally attractive option. Here, we propose an integrated management strategy that can handle the sizable, mildly activated fusion materials and minimize the radwaste burden for future generations. More specifically, we propose recycling and clearing the majority of fusion activated materials, if technically and economically feasible, and avoiding the geological disposal option. Demo and power plant designs should consider recycling and clearance as much as practically possible. Internationally, numerous fission industries are currently developing advanced techniques for spent nuclear fuel reprocessing and several regulatory agencies have issued guidelines for the free release of clearable materials. Both developments will be of great importance to fusion.
\end{abstract}

(C) 2013 The Japan Society of Plasma Science and Nuclear Fusion Research

Keywords: inertial fusion energy, fusion power plant, radioactive material, recycling, clearance, waste disposal, clearance index

DOI: $10.1585 /$ pfr.8.3404041

\section{Introduction}

One of the key challenges to the promotion of the nuclear industry worldwide is the political support for underground repositories and the availability of funding to build new ones. The disposal option attracted growing attention in the late 1960s as the preferred option for handling nuclear radwaste. To date, and after 50 years in the energy market, the nuclear industry continues to struggle with the management of radioactive waste from nuclear power plants. The reason is that, while radioactivity and toxic hazard can be estimated for many years, the prediction of geological and climatological conditions is less accurate for longer times into the future. This is probably one of the biggest advantages of fusion vs. fission: it does not produce large volumes of long-lived radionuclides. Moreover, future availability of disposal capacity and disposal cost is highly uncertain and regulatory standards tend to become more stringent with time. Therefore, recent efforts suggest minimizing the radioactive materials sent to repositories by reprocessing, if technically and economically feasible.

The past four decades witnessed serious inertial fusion energy (IFE) research delivering more than 50 power plant designs, mostly with laser drivers. Figure 1 dis-

author'se-mail: elguebaly@engr.wisc.edu

*) This article is based on the presentation at the Conference on Inertial Fusion Energy' 12. plays the timeline of 53 large-scale conceptual IFE designs developed to date in the US, Japan, Russia, and Europe. At present, there is worldwide interest in building laser fusion demos and commercial power plants by 2030$2040[1,2]$. With regard to the environmental impact of such plants, the pressing question is: what should we do with the radioactive materials generated during operation and after decommissioning? Even though fusion offers salient safety advantages relative to other sources of energy, the expected sizable quantity of mildly activated materials tends to rapidly fill the low-level waste repositories $[3,4]$. At present, many utilities that operate fission power plants store their radwaste onsite due to the limited and/or expensive offsite disposal option. Fusion cannot follow that precedent, as burying large volumes of fusion materials in geological repositories is impractical. Alternatively, more environmentally attractive approaches should be developed and incorporated at early design stages of a fusion demo and its successor power plants. The recycling (reuse of activated materials within the nuclear industry) and clearance (release to the commercial market, if materials contain only slight traces of radioactivity [5]) approaches emerged as the only viable solution that mitigates concerns about the geological conditions of repositories over millennia, radwaste burden for future generations, limited capacity of existing repositories, high disposal cost, and political difficulty of constructing new repositories. 


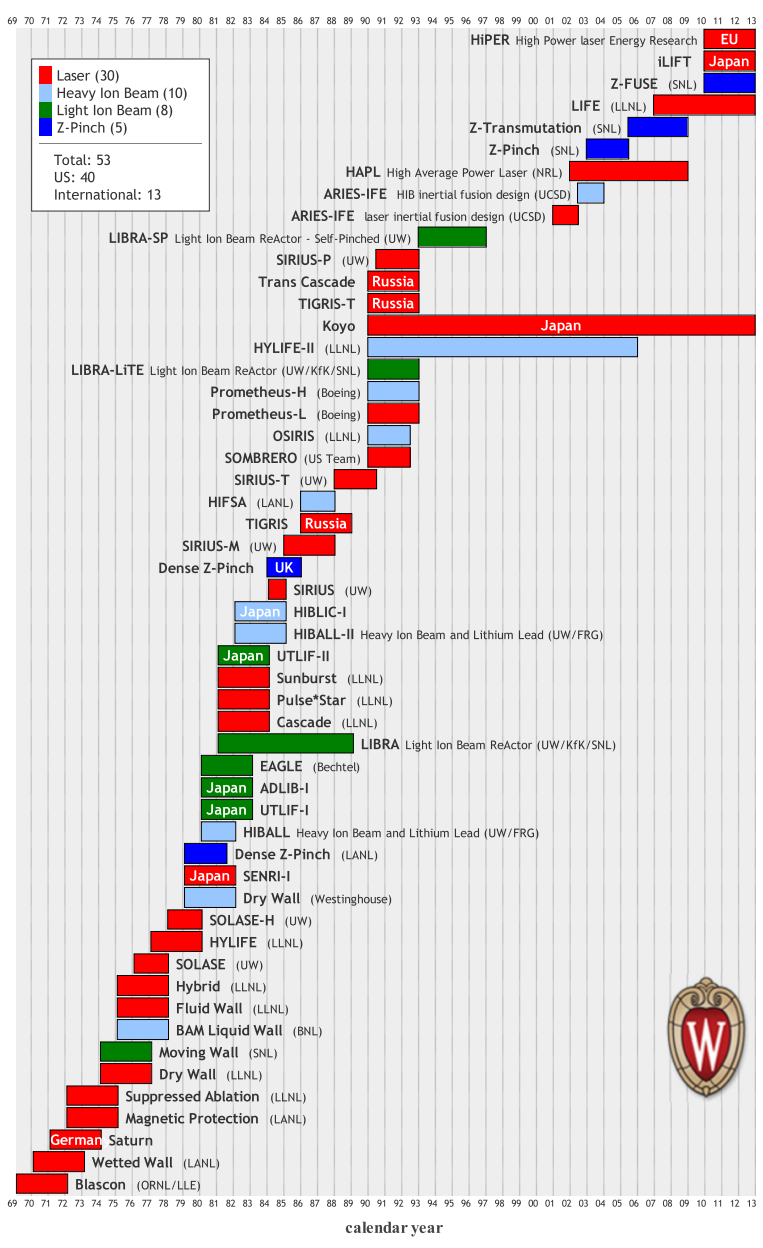

Fig. 1 Timeline of large-scale IFE power plant designs developed since the early 1970 s.

There is a growing international effort in support of recycling and clearance. Ever since the late 1990s, these scenarios have been applied to selected magnetic and inertial fusion power plant studies [3-11]. They became more technically feasible in recent years with the development of radiation-resistant remote handling $(\mathrm{RH})$ tools that can handle $10,000 \mathrm{~Sv} / \mathrm{h}$ and the introduction of the clearance category for slightly radioactive materials by the US Nuclear Regulatory Commission (NRC) [12], International Atomic Energy Agency (IAEA) [13], and other national nuclear agencies [3-5].

Most of the radioactive materials generated during fusion power plant operation are activated solid metallic materials from the main machine components (blanket and shield) and concrete of the biological shield, assuming liquid breeders (such as $\mathrm{LiPb}, \mathrm{Li}$, and Flibe) are refurbished for reuse by future fusion devices. The dominant radioactive material mass stream is generated during the decommissioning stage, but a significant amount - as far as radioactive inventory is concerned - is also produced during routine chamber replacements. A great deal of the decommissioning materials (up to $80 \%$, mainly the bioshield) has a very low activity concentration and can be cleared from regulatory control, especially when an extended period (up to $100 \mathrm{y}$ ) of interim storage is anticipated. The remaining $20 \%$ of the active materials could be disposed of as low-level waste or preferably recycled using a combination of advanced and conventional $\mathrm{RH}$ equipment. Most fusion active materials contain tritium that could introduce serious complications to the recycling process. A detritiation treatment prior to recycling is imperative for fusion components with high tritium content as well as for components contaminated with tritium, such as the bioshield.

Applying the recycling and clearance approaches to fusion designs is relatively simple from the science perspectives, but in some countries, it is a real challenge from policy, regulatory, and public acceptance perspectives. It is just a matter of time to develop the recycling/clearance regulations. They should be pursued despite the lack of details at present. To demonstrate the environmental benefits and impact on IFE designs of such radwaste management approaches, we applied all three scenarios (disposal, recycling, and clearance) to the most recent US inertial fusion power plant design: HAPL (High Average Power Laser) [14].

\section{Classification of HAPL Radioactive Materials}

The HAPL conceptual design employs a direct-drive target and dry wall chamber with 40 high intensity laser beams symmetrically compressing and heating the D-T target every 0.2 seconds to obtain a near continuous power production. Two chamber concepts delivering $1 \mathrm{GW}$ of electric power were pursued. In one approach, the chamber is made large enough ( $21 \mathrm{~m}$ in diameter) to withstand the emissions from the target. In the other, a relatively modest magnetic field is used to divert the ions (the most damaging component of the target emissions) into external dumps as shown in Fig. 2. Two structural materials have been considered for the $50 \mathrm{~cm}$ thick water-cooled shield: F82H and 316-SS steels. The maximum and minimum first wall (FW) locations from the target are 6 and $4.25 \mathrm{~m}$, respectively, with an average radius of $5.04 \mathrm{~m}$. For a fusion power of $1836 \mathrm{MW}$, the neutron wall loading peaks at $6 \mathrm{MW} / \mathrm{m}^{2}$ and averages at $4.3 \mathrm{MW} / \mathrm{m}^{2}$. The $\mathrm{FW} /$ blanket are replaceable every 3.3 full power years (FPY) while the shield and externals are life of plant components (40 FPY).

HAPL, as well as the majority of fusion power plants, generates only low-level waste (LLW) that requires nearsurface, shallow-land burial if all materials are carefully chosen to minimize the long-lived radioactive products. For most IFE fusion concepts, recycling of most components appeared technically attractive and judged, in many cases, a must requirement to control the radwaste stream $[8,11]$. However, even though reprocessing seemed technically feasible for the target materials, the disposal scheme emerged as the preferred option for economic reasons $[7,9]$. 


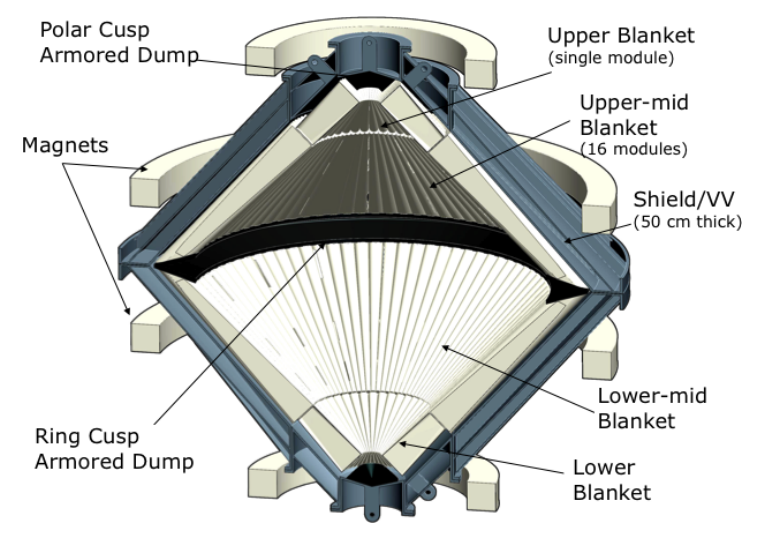

Fig. 2 Cutaway view of HAPL chamber with $\mathrm{SiC} / \mathrm{SiC}$ composite structure and $\mathrm{LiPb}$ breeder.

Figure 3 summarizes the waste disposal ratings (WDR) for HAPL components (FW/blanket, shield [with $\mathrm{F} 82 \mathrm{H}$ and 316-SS] and the bioshield that surrounds the chamber). According to the US-NRC regulations [15, 16], a WDR $<1$ means LLW and a WDR > 1 means high-level waste (HLW). The FW/blanket and F82H-based shield qualify as Class A and Class C LLW, respectively. The 316-SS structural material option for the shield should be excluded for generating HLW.

All HAPL components could be handled and eventually recycled with advanced or conventional RH equipment. The variation with time of the recycling dose rate shows a strong material dependence (refer to Fig. 4). The FW is shown as a separate component to provide the highest possible dose to the RH equipment. Storing the $\mathrm{FW} /$ blanket temporarily for several years helps drop the dose by a few orders of magnitude before recycling. This means the FW/blanket could be recycled immediately after replacement with advanced RH equipment or after a few years with conventional RH equipment. The shield requires a longer storage period ( $\sim 60$ years) to recycle with conventional equipment while hands-on recycling is feasible for the bioshield at $\sim 15 \mathrm{y}$ after decommissioning. Even though all metallics could potentially be reused following a heat treatment process [3], the technology needed to reuse the $\mathrm{SiC} / \mathrm{SiC}$ composites does not exist at present. Hopefully, future advances in recycling techniques could allow the reuse of ceramics to fabricate the matrix as well as the fiber of composites.

A component qualifies for clearance if the clearance index (CI) drops below one at any time during a period of $100 \mathrm{y}$ following decommissioning [5]. For HAPL, as well as for most fusion designs, the CIs for all internal components (such as FW, blanket, and shield) exceed unity by a wide margin as shown in Fig. 5. Such internal components should be disposed of in repositories or preferably recycled. The inner $50 \mathrm{~cm}$ thick layer of the bioshield could qualify for clearance if the shield is thickened by $\sim 10 \mathrm{~cm}$. Alternatively, fabricating the ordinary concrete without the $8.34 \mathrm{wt} \%$ Ca will eliminate the production of $\mathrm{Ca}-41$ and al-

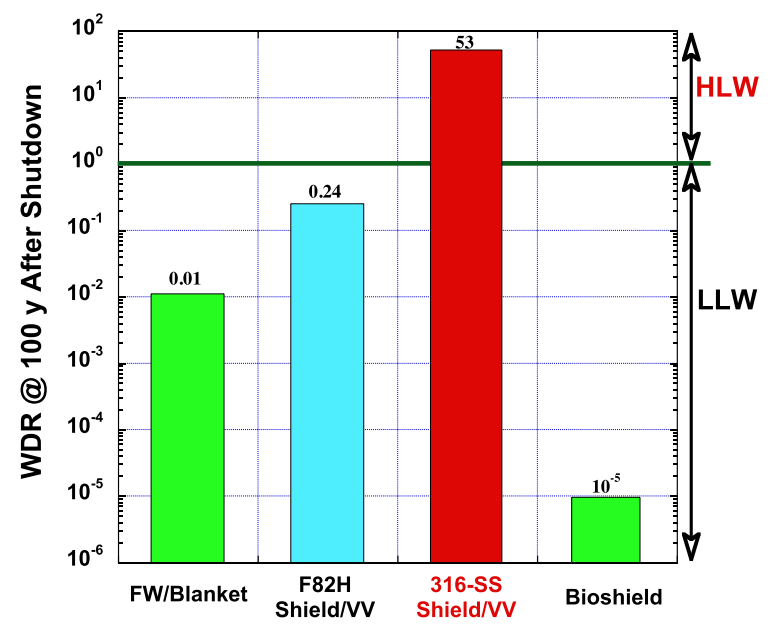

Fig. 3 Waste disposal ratings of fully compacted HAPL components.

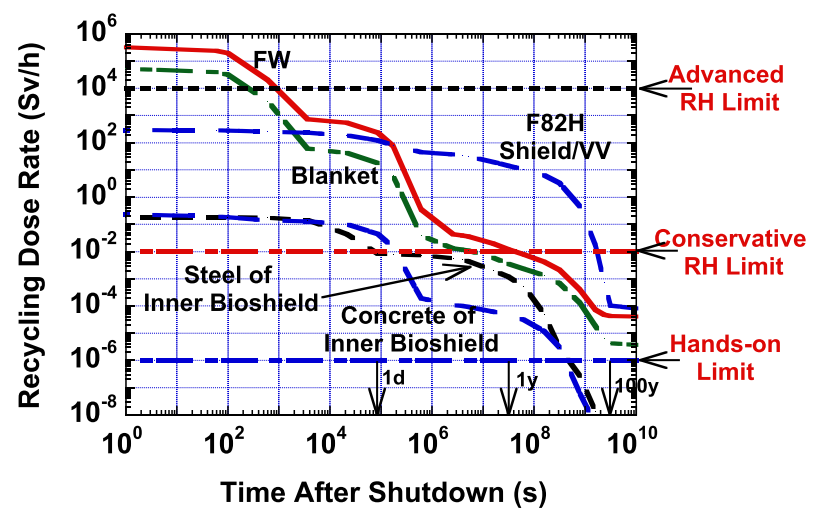

Fig. 4 Recycling dose rate for selected HAPL components.

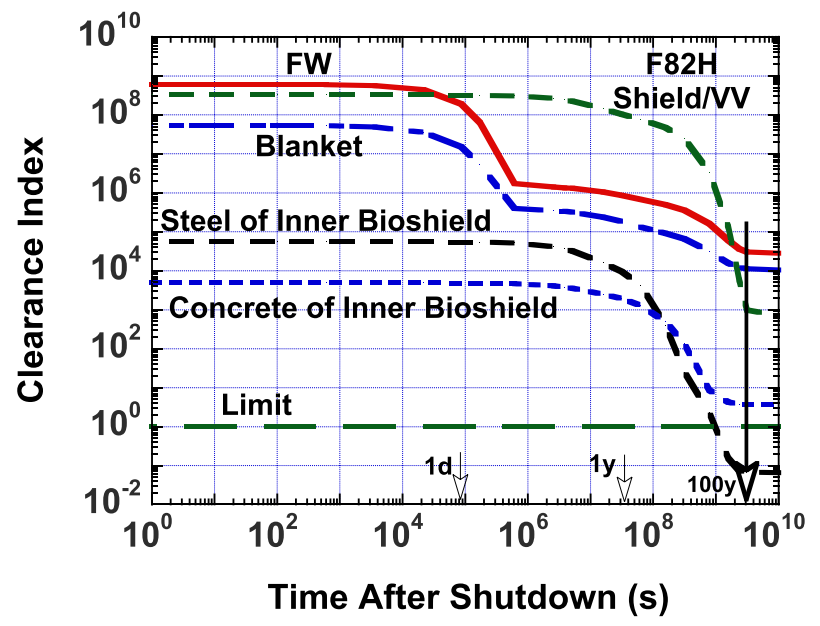

Fig. 5 Variation of clearance index with time after shutdown.

low clearing the concrete in $50 \mathrm{y}$. Fortunately, the rest of the bioshield $(\sim 2 \mathrm{~m})$ qualifies for clearance, representing the largest single component of the decommissioned radwaste. 


\section{Key Recycling/Clearance Issues and Needs}

There is no doubt that recycling and clearance have a key role to play to help minimize the volume of active materials assigned for geological disposal. In order to provide a broader perspective of the relevant issues involved in the recycling process and enhance prospects for a successful integrated management strategy, we identified the key issues and needs for recycling and clearance as well as for geological disposal. As a step forward, a dedicated research and development (R\&D) program should tackle these issues, allowing further optimization of the radwaste management scheme and enhancing the possibility of recycling and clearance as much as practically possible.

\subsection{Recycling issues and needs}

Recycling is a real metric of whether the nuclear industry is serious about reducing its radioactive waste. Currently, there is no unanimous consensus within the fusion community regarding recycling. The debate is similar to that occurring within the fission community with some arguing recycling could result in substantial technological difficulties, while others claiming the environmental benefits far outweigh any adverse effects. At present, a reasonable recycling experience exists within the nuclear industry. With the renaissance of nuclear energy, it seems highly likely that recycling technology will continue to develop at a fast pace to support the mix-of-oxides (MOX) fuel reprocessing system and expand the worldwide use of fission nuclear power. Fusion has a much longer timescale than 20 years and will certainly benefit from the ongoing fission recycling experience and related governmental regulations.

Recycling issues:

- Separation of various activated materials from complex components

- Radiochemical or isotopic separation processes for some materials, if needed

- Treatment and remote re-fabrication of radioactive materials

- Radiotoxicity and radioisotope buildup and release by subsequent reuse

- Properties of recycled materials? Any structural role? Reuse as filler?

- Handling of T containing materials during recycling

- Management of secondary waste. Any materials for disposal? Volume? Radwaste level?

- Energy demand for recycling process

- Cost of recycled materials

- Recycling plant capacity and support ratio.

Recycling needs:

- R\&D program to address recycling issues

- Radiation-resistant remote handling equipment

- Reversible assembling process of components and constituents (to ease separation of materials after use)

- Efficient detritiation system

- Large and low-cost interim storage facility with decay heat removal capacity

- Nuclear industry should accept recycled materials

- Recycling infrastructure.

\subsection{Clearance issues and needs}

There is widespread agreement between the USNRC [12] and IAEA [13] on the primary dose standard and the negligible risk the cleared materials present to individuals. However, the clearance limits developed thus far show a wide variation for almost all radioisotopes. Other shortcomings include the lack of consideration for numerous fusion-related radioisotopes and their possible effect on the clearance index prediction. Despite these differences, efforts by all organizations will continue to convince industrial as well as environmental groups that clearance of slightly radioactive solids can be conducted safely with no risk to the public health [5].

Clearance issues:

- Discrepancies between proposed US-NRC and IAEA clearance standards [5]

- Impact on clearance index prediction of missing radioisotopes

- Radioisotope buildup and release by subsequent reuse.

Clearance needs:

- Official clearance limits issued by legal authorities

- Accurate measurements and reduction of impurities that deter clearance of in-vessel components

- Reversible assembling process of components and constituents

- Large and low-cost interim storage facility

- Clearance infrastructure

- Clearance market (some experience exists in several EU countries: Sweden, Germany, Spain, and Belgium. At present, US industry does not support unconditional clearance claiming it could erode public confidence in US products and damage US markets [5]).

\subsection{Disposal issues and needs}

Reference [3] summarizes the status of geological repositories in the US, Europe, and Japan. As expected, there are commonalities and differences internationally. Thus, identifying a common basis for a universal repository seems impossible because of the great diversity in technical and geological repository settings, and in disposal requirements (specific radioactivity, contact dose rate, decay heat level, etc.). Nevertheless, we made a number of observations and provided below the most critical disposal issues and needs facing the international fusion community. 
Disposal issues:

- High disposal cost (for preparation, characterization, packaging, interim storage, transportation, licensing, and disposal)

- No HLW repositories, except in Russia

- Limited capacity of existing LLW repositories

- Political difficulty of building new repositories

- Prediction of repository's conditions for long time into future

- Radwaste burden for future generations.

Disposal needs:

- Revised activity limits for HLW and LLW issued by legal authority

- Repositories designed for T-containing materials

- Reversible disposal process and retrievable waste (to gain public acceptance and ease licensing).

\section{Maturation of Recycling and Clear- ance Approaches}

The fusion program should start now to develop a recycling approach before designing/building Demo (by 2030) and a clearance approach before decommissioning power plants (by 2070), hoping that all countries will be progressive with respect to recycling/clearance perspectives. As such, we recommend the following general guidelines for the maturation of the recycling and clearance approaches.

Fusion designers should:

- Minimize radwaste volume by clever designs

- Promote environmentally attractive scenarios such as recycling and clearance, avoiding geological disposal

- Continue addressing critical issues for all three options

- Address technical and economical aspects before selecting the most suitable radwaste management approach for any fusion component, especially target materials.

Nuclear industry and regulatory organizations should:

- Continue developing advanced radiation-resistant remote handling equipment capable of handling > $10,000 \mathrm{~Sv} / \mathrm{h}$

- Issue official guidelines for unconditional release of fusion clearable materials

- Accept recycled materials from dismantled nuclear facilities

- Continue national and international efforts to convince industrial and environmental groups that clearance can be conducted safely with no risk to public health.

\section{General Remarks}

Numerous fusion studies indicated recycling and clearance are technically feasible for any fusion device employing low-activation materials, using advanced radiation-resistant remote handling equipment, and having clearance guidelines for slightly radioactive materials. However, such approaches are relatively easy to envision and apply from a science perspective, but a real challenge, particularly in the US, from policy, regulatory, and public acceptance perspectives. To make these approaches a reality, major rethinking, education, and research should be developed and pursued. In the near future, the US fusion development program should be set up to accommodate this new recycling/clearance strategy as proper handling of activated materials is important to the future of fusion energy.

It is just a matter of time to develop the recycling/ clearance technology and regulations. At present, the experience with recycling/clearance is limited, but will be augmented significantly by advances in fission reactor dismantling, used fuel reprocessing, and bioshield clearing before fusion is committed to commercialization in the $21^{\text {st }}$ century. While there is no US official regulation for recycling and clearance of activated materials, there has been some progress made. For instance:

- The US-NRC is currently developing guidelines for clearable materials

- Limited scale recycling within the nuclear industry has been proven feasible at several US national laboratories

- Remote handling equipment operated well at high doses around 10,000 Sv/h since the 1960s

- The free release of clearable materials has been performed since the 1990s on a case-by-case basis during decommissioning projects

- Recently in 2010, the Department of Energy required decontamination of 15,300 tons of radioactive nickel and recycling into products that will be used in radiologically-controlled applications

- MOX fuel fabrication facility in South Carolina is $\sim 50 \%$ complete and will start operations in 2016 .

Internationally, numerous fission industries are currently developing advanced techniques for used nuclear fuel reprocessing while several regulatory agencies have issued guidelines for clearance. Such developments at the national and international levels will be of great importance to fusion, but adaptation is necessary to fusion needs (radiation level, component size, weight, etc.).

While enjoying the benefits of fusion energy, the current generation of fusion designers should develop an integral strategy to handle the majority of fusion radioactive materials without imposing undue risks and burdens on future generations. Such a strategy should promote the recycling and clearance and avoid geological disposal, hoping the public will be progressive with respect to recycling/clearance perspectives.

[1] M. Dunne (Lawrence Livermore National Laboratory), private communications (Apri1 2012).

[2] L. El-Guebaly, "Basic Concepts of Thermonuclear Fusion," Chapter 5 in Nuclear Energy Encyclopedia: Science, Technology, and Applications, Steven B. Krivit and Jay H. Lehr, eds. (John Wiley \& Sons, 2011) ISBN 978-0-470-89439-2. 
[3] L. El-Guebaly, V. Massaut, K. Tobita and L. Cadwallader, Fusion Eng. Des. 83, Issues 7-9, 928 (2008).

[4] M. Zucchetti, L. Di Pace, L. El-Guebaly, B.N. Kolbasov, V. Massaut, R. Pampin and P. Wilson, Fusion Sci. Technol. 52, No. 2, 109 (2009).

[5] L. El-Guebaly, P. Wilson and D. Paige, Fusion Sci. Technol. 49, 62 (2006).

[6] L. El-Guebaly, Nucl. Fusion 47, 485 (2007).

[7] L. El-Guebaly, P. Wilson, D. Henderson and A. Varuttamaseni, Fusion Sci. Technol. 46, No. 3, 506 (2004).

[8] L. El-Guebaly, Fusion Sci. Technol. 47, No. 3, 544 (2005).

[9] L. El-Guebaly, P. Wilson, M. Sawan, D. Henderson and A. Varuttamaseni, Nucl. Instrum. Methods Phys. Res. A 544, 104 (2005).

[10] M. Zucchetti, L. El-Guebaly, R.A. Forrest, T.D. Marshall, N.P. Taylor and K. Tobita, J. Nucl. Mater. 367-370, 1355 (2007).

[11] S. Reyes, J. Sanz and J. Latkowski, Fusion Eng. Des. 63-
64, 257 (2002).

[12] Nuclear Regulatory Commission, "Radiological Assessments for Clearance of Materials from Nuclear Facilities," Washington, D.C., Main Report, NUREG-1640 (2003). Available at: http://www.nrc.gov/reading-rm/ doc-collections/nuregs/staff/sr1640/

[13] International Atomic Energy Agency, "Application of the Concepts of Exclusion, Exemption and Clearance," IAEA Safety Standards Series, No. RS-G-1.7 (2004). Available at: http://www-pub.iaea.org/MTCD/publications/PDF/ Pub1202_web.pdf

[14] J.D. Sethian et al., IEEE Trans. Plasma Sci. 38, No. 4, Part 2, 690 (2010).

[15] Nuclear Regulatory Commission, 10CFR61, "Licensing Requirements for Land Disposal of Radioactive Waste," Federal Register FR47, 57446 (1982).

[16] S. Fetter, E.T. Cheng and F.M. Mann, Fusion Eng. Des. 13, 239 (1990). 